\title{
ASSESSMENT OF CROSS COMPATIBILITY IN THREE STRAINS OF PLEUROTUS SPECIES AND YIELD ATTRIBUTES OF THE SURVIVING PROGENIES
}

\author{
Ogunleye, R. I., "Bankole, F.A., Olaoye, G., and Fawole, O.B. \\ Department of Agronomy, University of Ilorin, \\ PMB 1515, llorin, Nigeria. \\ *Corresponding Author: jadesolaoluwa@yahoo.com
}

\begin{abstract}
Despite the upsurge in mushroom consumption in Nigeria, breeding of new strains for improved quality, early maturity and biological efficiency is a new concept. This study investigated cross-compatibility among three mushroom parental strains (Pleurotus ostreatus, P. tuber-regium and Lentinus edodes) and assessed yield attributes in parents and the progenies of compatible strains - ( $P$. ostreatus and $L$. edodes). The crosses were carried out at the Department of Biology, Kogi State University, Anyigba, Kogi State, Nigeria using the dual culture technique. Among the twenty-seven combinations, only five (5) hybridized successfully. Crosses between $P$. tuber-regium and the other two strains ( $P$. ostreatus and $L$. edodes) failed to yield viable progenies while the cross between $P$. ostreatus (po) and $L$. edodes (le) yielded five (5) new strains. Data collected on morphological and yield attributes of the compatible parents and the new strains revealed that three (3) strains (po1 $x$ le 1 , po3 $\times$ le2 and po3 $x$ le3) produced white fluffy colony growth morphology which represented the characters of $P$. ostreatus while the remaining two strains (po2 $\times$ le 1 and po $2 \times$ le3) had milky, appressed morphology, representing the attributes of $L$. edodes. The strain from cross combination po3 $x$ le3 completed spawn run in 37 days which was the fastest $(\rho<0.05)$ among the strains and also exhibited superiority $(\rho<0.05$ or $\rho<0.01)$ for all other attributes including fresh yield and biological efficiency over other strains and the two parents. Two other strains viz. po2 $x$ le 3 and po3 $x$ le2 also exhibited significantly $(\rho<0.05)$ higher yield and biological efficiency than either of the parental strains. These new strains can be exploited for commercial production of improved mushrooms in Nigeria.
\end{abstract}

Key words: Cross Compatibility, Pleurotus, Dual Culture, Yield, Biology efficiency 


\section{INTRODUCTION}

Mushrooms are fleshy, spore-bearing reproductive structure of fungi which are important as human food due to its nutritional and medicinal properties (Bllal et al., 2010). They are universally recognized as sources of high quality protein that can be produced with greater biological efficiency than animal protein (Wang et al., 2001). Although they are commonly found in the wild, mushrooms can also be grown under household condition in a sustainable way to create a source of livelihood and improved nutrition. Since it requires low resources and can be grown all year round, mushroom cultivation is the most efficient and economically viable biotechnology for the conversion of lignocellulose waste materials into high quality protein food and fertilizers (Jaradat, 2010).

Edible mushrooms particularly Pleurotus species are known to be among the largest of fungi which grow on different agricultural wastes producing fruiting bodies and in the process, convert the substrates into digestible protein-rich substance which is suitable for animal feed, soil conditioners and fertilizer. The genus Pleurotus (oyster mushroom) comprises some of the most popular edible mushrooms because of their favourable organoleptic and medicinal properties as well as vigorous growth and undemanding cultivation conditions (Gregori et al., 2007). The growth period of $P$. ostreatus is usually shorter than that of other edible mushrooms (Sánchez, 2010).

Mushroom breeding has great potential as a means of growing a highly nutritious food with excellent taste from substrates that are in abundance and grossly underutilized. A corollary is that the development of new and improved strains of mushroom with better quality, early maturity and biological efficiency will meet the increasing demand of the people and become a major landmark for the establishment of commercial production of new mushroom cultivars with novel and improved traits (Larraya et al., 2003). This is also expected to provide the mushroom industry with options for solving food problems and increase the efficiency of mushroom production.

Several approaches such as protoplast culture, spore germination, ultra violet (UV) light and ethyl methyl sulfonate (as mutagens) among others have been used to breed new strains of mushroom (Aswini et al., 2014; Sharma and Sharma, 2014). However, the protoplast fusion technique has 
proven to be the most feasible method for inter-specific and inter-generic hybridization for strain improvement among edible mushrooms. For example, Djajanegara and Masduki (2010) as well as Parani and Eyini (2010) reported success of protoplast fusion in obtaining improved $F_{1}$ hybrids from the cross of $P$. eous and $P$. flabellatus. Luk and Chiu (2005) also utilized the protoplast fusion approach to generate interspecific hybrids between Ganoderma lucidum and $G$. tsugae to enhance high and low temperature tolerance mushroom strain. In their own study, Chakraborty and Sikdar (2010) used intergeneric protoplast fusion between Calocybe indica and $P$. florida to generate hybrid strains with improved qualitative and quantitative sporophore of the milky mushroom. This technique has also been used to derive improved strains with high biological efficiency ranging between 119 and $153 \%$ from a cross between $P$. eryngii and $L$. edodes neohaplonts, apart from a wide variety of morphologies including different pileus size, colours and shapes, large, thick and fleshy stipe, resulting in their suitability as strains for a commercial exploitation (Ramirez et al., 2011). Other successful studies in protoplast fusion include those which produced strains of $P$. ostreatus that are adapted to warm environment (Gaitán-Hernández and Salmones, 2008) hybrid mushrooms which produces anti-thrombin agents obtained from a cross between Laetiporus sulphureus and $H$. marmoreus (Okamura et al., 2000) and another hybrid obtained from fusion of protoplast of $P$. florida and Volvariella volvacea with immunoactive polysaccharide (Patra et al., 2011).

Although mushroom is a popular delicacy in many communities especially in the southern Nigeria where it is exploited for food and medicinal purposes (Okhoya et al., 2010), there is yet no breeding programme designed for the development of high yielding and nutritious mushrooms strains in the country. In the study reported herein, crosses were effected among three species of mushroom $-P$. ostreatus, $P$. tuber-regium and Lentinus edodes with the objectives to (i) determine the level of compatibility between the three species and (ii) evaluate the new strains for their yield traits and productivity. 


\section{MATERIALS AND METHODS}

The experiment was carried out at the Department of Biological Science Research Laboratory, Kogi State University, Anyingba, Nigeria. Three species of mushroom Pleurotus tuber regium, $P$. ostreatus and Lentinus edodes were used for this study. The spores of $P$. ostreatus mushroom was obtained from the National Biotechnology Research Development Agency, Ogbomosho, Nigeria while those of $P$. tuber-regium and L. edodes were obtained from the Department of Biology, Kogi State University, Anyingba.

\section{Test for Compatibility}

Spore cultures each derived from three Mushroom strains were selected at random and compatibility test was carried out with a combination of cultures. The dual culture technique was used to make crosses among the homokaryotic cultures. This was done by insertion of a thriving mycelia of cultures of single spores of each of the strains about $1 \mathrm{~cm}$ away from each other in an agar made of potato dextrose contained in a petri dish of about $100 \mathrm{~mm}$ (Badalyan et al., 2002). The combination was in three replicates, set up as a completely randomized design (CRD). After the union of the homokaryons a mycelia sample was removed and placed in to fresh agar medium and advanced into heterokaryotic mycelia. Upon observation of a network of dikaryotic hyphae clamp, at the growing edges of the strains interacting, the crosses were deemed successful. The hybridized strains were kept under room temperature. Based on the growth performance of the hybrids, only cross combinations between $P$. ostreatus and $L$. edodes successfully hybridized while crosses between $P$. ostreatus and $P$. tuberregium as well as between $P$. tuber regium and $L$. edodes were not compatible (Table 1). Consequently, only the successfully hybridized strains and their parents were in subsequent use for further investigation.

\section{Production of Spawns}

The strains of the parents and the $F_{1}$ hybrids considered successful were established on sorghum (Sorghum bicolor) spawn substrate mixed with Calcium Carbonate at one percent $(1 \%)$. The combination was optimized adjusted to a moisture of $60 \%$ according to the protocol described by Yang (1986) and then put in bottles. The bottles were autoclaved and thereafter were inoculated with the strains and nurtured in the dark at room temperature while enclosed in polyethylene bags (Plate 1). The treatments were in three replicates and arranged in a similar manner as for the 
compatibility test. The development of the mycelia was visually detected and the number of days required for the spawn substrate to be colonized entirely by each of the strain was referred to as the percentage of medium colonization.

\section{Fruiting and Harvesting:}

The growth medium contained saw dust (78\%), wheat bran (20\%), $\mathrm{CaCO} 3$ $(2 \%)$ with adequate water. The mixture was placed in various polypropylene bags and their mouths were covered by insertion of water absorbing cotton with the aid of plastic rings. The bags were placed in an autoclave at $121^{\circ} \mathrm{C}$ at 15-20 psi pressure and thereafter allowed to cool. The bags were inoculated after sterilization with the spawns of the parental and successful hybrid strains at the rate of $5 \%$ per bag according to the dry weight of substrates and then incubation for spawn run was carried out under complete darkness at the room temperature. The experiment was also laid out in CRD with three replicates. The bags were placed in the cropping room for initiation of fruiting after the mycelia reached the bottom and watered daily at cropping. During the period of the study, mature fruit bodies were harvested three times.

\section{Data Collection}

Data were collected on days to completion of spawn run, number of fruit bodies developed in bags inoculated with each of the strain, total weight of fruiting bodies (flush) using a weighing balance and productivity (\%) designated as the biological efficiency of the strain. This was calculated as the total weight of fruit bodies/ Total weight of substrate spawn $\times 100$ (Musakhail et al., 2011).

\section{Data Analysis}

Data collected were analyzed using GENSTAT and means were separated by Least Significant Difference according to Steel and Torrie (1980).

\section{RESULTS AND DISCUSSION \\ Cross Compatibility}

The cross combinations of $P$. ostreatus $\times \quad P$. tuber-regium and $P$. tuberregium $x$ L. edodes was unable to produce any successful hybrid while the cross between $P$. ostreatus and $L$. edodes successfully hybridized yielding five (5) new strains (Table 1). The incompatibility reaction between $P$. tuber 
regium and the other two parental strains had earlier been reported by Vilgalys et al., (1996) who suggested that $P$. tuber regium should be expunged from among the other Pleurotus species. The inability of $P$. tuber regium to produce successful hybrids with $P$. ostreatus and $L$. edodes may as a result of pairing difficulties encountered during meiosis suggesting that $P$. tuber regium is genetically diverse from the other two species. Hyphal fusion between two homokaryotic mycelia, leading to the development of a heterokaryotic mycelium which is fertile; This development is accompanied by nuclear division and formation of septum in the connection of clamps is a proof of compatibility between the strains. The hybridization between $P$. ostreatus and $L$. edodes is further exemplified by two (2) types of clamp connections - a single clamp connection as well as double clamp connections (Plate 2).

\section{Colony Morphology on PDA Medium}

The morphology and colony growth characteristics of the parents and the five (5) new strains derived from the $P$. ostreatus and $L$. edodes crosses are presented in Table 2. Three (3) of the new strains (po1 x le1, po2 $x$ le1 and po3 $\times$ le3) exhibited the morphological attributes and growth colony of $P$. ostreatus (white, smooth texture and long stipe) while the remaining two strains exhibited attributes of $L$. edodes (milky, rough texture and short stipe). However, with respect to colony characteristics, the results revealed that three (3) of the new strains (po1 x le1, po3 x le2 and po3 $\times$ le3) exhibited the colour and mycelia appearance of $P$. ostreatus (white and fluffy) while the remaining two (2) strains (po2 $\times$ le 1 and po2 $\times$ le3) although had the milky colour of $L$. edodes expressed new mycelia which differed from those of the parents.

One of the new strains (cross po3 $x$ le3) completed spawn run faster than the others including the two parental strains (Table 3 ) which was also accompanied by production of a large basidiocarp (Plate 3). One of the parents $(P$. ostreatus) also completed the spawn run faster than the remaining new four (4) strains and the second parent ( $L$. edodes) which was the latest in completing spawn run. The variance in number of days it took to complete the spawn run among the mushroom genotypes was seven (7) days and the time required from the day of spawning to first harvest was also the least in the strains resulting from cross combinations po $3 x$ le 3 and po $2 x$ le1 with a range of four (4) days between these strains and $L$. edodes. 
However, there was no consistent trend among the strains for these two attributes since strains po $2 \times$ le 1 and po $3 \times$ le 2 which were the slowest in spawn run attained first fruit harvest earlier than the other strains except po3 $x$ le3 with which were similar for this trait. Although previous studies have shown that spawn run and time taken to fruit body harvest is dependent on the growth medium, log size, spawn quality, strain, moisture, temperature and other variables (Roysne and Bahler, 1989; Ramirez et al., 2011), this study did not vary the substrate. Therefore, the observed differences among the strains for these characters are likely due to recombination among the genes in the parental strains which manifested in the $F_{1}$ hybrids. Additionally, the first flush of yield was at its peak in all the genotypes while the final flush was the least (Figure 1). Two of the new strains (po3 $x$ le 3 and po2 $x$ le3) in that order, had higher flushes of yield than either parent or the remaining strains at each period of measurement. All the new strains yielded higher than the low yielding parent ( $L$. edodes) by between $24.57 \mathrm{~g}$ and $3.78 \mathrm{~g}$ (first flush), $7.8 \mathrm{~g}$ and $1.2 \mathrm{~g}$ (second flush) as well as $6.63 \mathrm{~g}$ and $1.02 \mathrm{~g}$ (third flush) representing 25.18-4.72, 24.35-4.72 and 24.38-4.72 percent (\%) superiority of the new strains respectively over $L$. edodes. This suggests that $P$. ostreatus carries the allele for the expression of these traits in the dominant form.

The cumulative flush yields for each genotype also revealed a significantly higher flush yield in the two new strains (po3 $x$ le3 and po2 $x$ le3). Although, number of fruit bodies remained unaffected in the newly developed strains, there was an increase in weight of the fruit bodies recorded for the new strains compared to weight of fruiting bodies from either parent except for cross combinations po $2 \times$ le 1 and po $1 \times$ le 1 with relatively lower yields than $P$. ostreatus. In other words, the three new strains are superior to either parent in productivity and quality of fruit bodies, which agrees with earlier observations of Bak et al., (1996) who reported higher productivity and quality of fruit bodies in 60 strains of shiitake raised from four parent strains compared to their parents.

Biological efficiency is an indication of the strain's capacity to convert the medium into a form that is more usable (Kumara and Edirimanna, 2009). The range in biological efficiency among the mushroom genotypes was approximately $20 \%$ with cross combination po $3 \times$ le 3 which recorded the highest fresh yield also having the highest biological efficiency of 80.0. However, the values reported for biological efficiency in this study are lower 
than those recorded by Gaitán-Hernández and Salmones (2008) who reported a range of 74.4 to 320 in L. edodes strains raised on wheat straw inoculated with three types of spawn but higher than values reported by Musakhail et al., (2011) for $P$. ostreatus raised on gram powder amendment substrate. Three of the new strains exhibited superiority for biological efficiency over the parents suggesting recombination of alleles which although present in the parental strains were probably covered by their respective dominant alleles. Consequently, the three new strains may be referred to as transgressive segregants having exhibited values that are higher than those of the better parent. Furthermore, all the new strains also had higher biological efficiency ranging from 20.5 and $3.5 \%$ than $L$. edodes which is the least efficient.

Buah et al. (2010) as well as Masarirambi et al. (2011) noted that spawn running is an indication of how fast the substrate is utilized by the mycelia. Kumara and Edirimanna (2009) attributed maximum utilization of substrate to the kind of strain grown on a specific medium such that some strains may perform well in one medium while others do not. In this study, three of the new strains derived from $P$. ostreatus and $L$. edodes crosses apart from days to completion of spawn running, exhibited superiority for all the attributes measured suggesting that they exhibited better utilization of the substrate used.

In conclusion, the three new strains of mushroom which exhibited superiority for yield and quality attributes offer opportunities for commercialized production of nutritious and quality mushrooms at a much lower cost compared to earlier approaches. The study also confirmed earlier report of Vilgalys et al. (1996) who suggested the removal of $P$. tuber-regium from other species of Pleurotus.

\section{ACKNOWLEDGEMENTS}

We express our sincere gratitude to the National Biotechnology Research Development Agency, Ogbomosho and the Department of Biology, Kogi State University, Anyigba for providing the spores of strains of mushrooms used for the study and for guidance of the staff of the Department of Biology, Kogi State University, during the course of the study. 
Table 1: Series of Compatibility reactions between three strains of Pleurotus.

\begin{tabular}{|c|c|c|c|}
\hline \multirow{2}{*}{$\begin{array}{lllll}\text { Crosses } & & & \\
P . \quad \text { ostreatus } & \times & P . & \text { tuber } \\
\text { reaium } & \end{array}$} & \multicolumn{3}{|c|}{ Compatibility Reaction } \\
\hline & 1 & 2 & 3 \\
\hline 1 & - & - & - \\
\hline 2 & - & - & - \\
\hline 3 & - & - & - \\
\hline P. ostreatus and L. edodes & 1 & 2 & 3 \\
\hline 1 & + & - & - \\
\hline 2 & + & - & + \\
\hline 3 & - & + & + \\
\hline P. tuber regium $\times$ L. edodes & 1 & 2 & 3 \\
\hline 1 & - & - & - \\
\hline 2 & - & - & - \\
\hline & - & - & \\
\hline
\end{tabular}

Note: + = Compatible cross; - = Incompatible cross.

Table 2: Morphology of basidiocarp and colony growth characteristics (on Potato Dextrose Agar medium) of parents and new mushroom strains derived from Pleurotous ostreatus $\mathrm{x}$ Lentinus edodes cross.

\begin{tabular}{|c|c|c|c|c|c|c|}
\hline Strains & & Morp & ological A & ibutes & Colo & Characteristics \\
\hline Parents & & Colour & Texture & Stipe & & \\
\hline P. ostreatus & & White & Smooth & Long & White & Fluffy \\
\hline L. edodes & & Milky & Rough & Short & Milky & Appressed \\
\hline P. tuber regium & & White & Rough & Long & --- & --- \\
\hline New strains ${ }^{+}$ & Cross code & & & & & \\
\hline Strain 1 & Po1 $\times$ Le1 & White & Smooth & Long & White & Fluffy \\
\hline Strain 2 & Po2 x Le1 & White & Smooth & Long & Milky & Appressed \\
\hline Strain 3 & Po2 x Le3 & Milky & Rough & Short & Milky & Appressed \\
\hline Strain 4 & Po3 x Le2 & Milky & Rough & Short & White & Fluffy \\
\hline Strain 5 & Po3 x Le3 & White & Smooth & Long & White & Fluffy \\
\hline
\end{tabular}

+ ; Successful hybridization between $P$. ostreatus $\times$ L. edodes. 
Table 3: Days to completion of spawn run, pinhead formation and average number of fruiting bodies to parents and strains derived from $P$. ostreatus $\times$ L. edodes.

\begin{tabular}{|c|c|c|c|c|c|c|}
\hline Strains & & $\begin{array}{l}\text { Days to } \\
\text { completion } \\
\text { of spawn } \\
\text { running } \\
\text { (no) }\end{array}$ & $\begin{array}{l}\text { Time } \\
\text { to first } \\
\text { harvest } \\
\text { days) }\end{array}$ & $\begin{array}{l}\text { Number } \\
\text { of } \\
\text { fruiting } \\
\text { bodies } \\
\text { (no) }\end{array}$ & $\begin{array}{l}\text { Fresh } \\
\text { yield } \\
\text { (g) }\end{array}$ & $\begin{array}{l}\text { Biological } \\
\text { Efficiency } \\
(\%)\end{array}$ \\
\hline \multicolumn{7}{|l|}{ Parents } \\
\hline $\begin{array}{l}P . \\
\text { ostreatus }\end{array}$ & & 38 & 9 & 12 & 130 & 65.0 \\
\hline $\begin{array}{l}\text { L. } \\
\text { edodes }\end{array}$ & & 45 & 12 & 10 & 121 & 60.5 \\
\hline $\begin{array}{l}\text { New } \\
\text { strains }^{+}\end{array}$ & $\begin{array}{l}\text { Cross } \\
\text { code }\end{array}$ & & & & & \\
\hline Strain 1 & $\begin{array}{l}\text { Po1 } x \\
\text { Le1 }\end{array}$ & 41 & 11 & 11 & 129 & 64.5 \\
\hline Strain 2 & $\begin{array}{l}\text { Po2 } x \\
\text { Le1 }\end{array}$ & 42 & 8 & 6 & 127 & 63.5 \\
\hline Strain 3 & $\begin{array}{l}\text { Po2 } x \\
\text { Le3 }\end{array}$ & 40 & 10 & 10 & 150 & 75.0 \\
\hline Strain 4 & $\begin{array}{l}\text { Po3 } x \\
\text { Le2 }\end{array}$ & 42 & 9 & 10 & 140 & 70.0 \\
\hline Strain 5 & $\begin{array}{l}\text { Po3 } x \\
\text { Le3 }\end{array}$ & 37 & 8 & 12 & 160 & 80.0 \\
\hline Mean & & 40.71 & 9.57 & 10.14 & 136.7 & 68.36 \\
\hline Range & & 7 & 4 & 6 & 39 & 19.5 \\
\hline $\begin{array}{l}\text { LSD } \\
\alpha 0.05\end{array}$ & & 3.50 & 3.25 & 8.61 & 0.69 & 0.38 \\
\hline
\end{tabular}




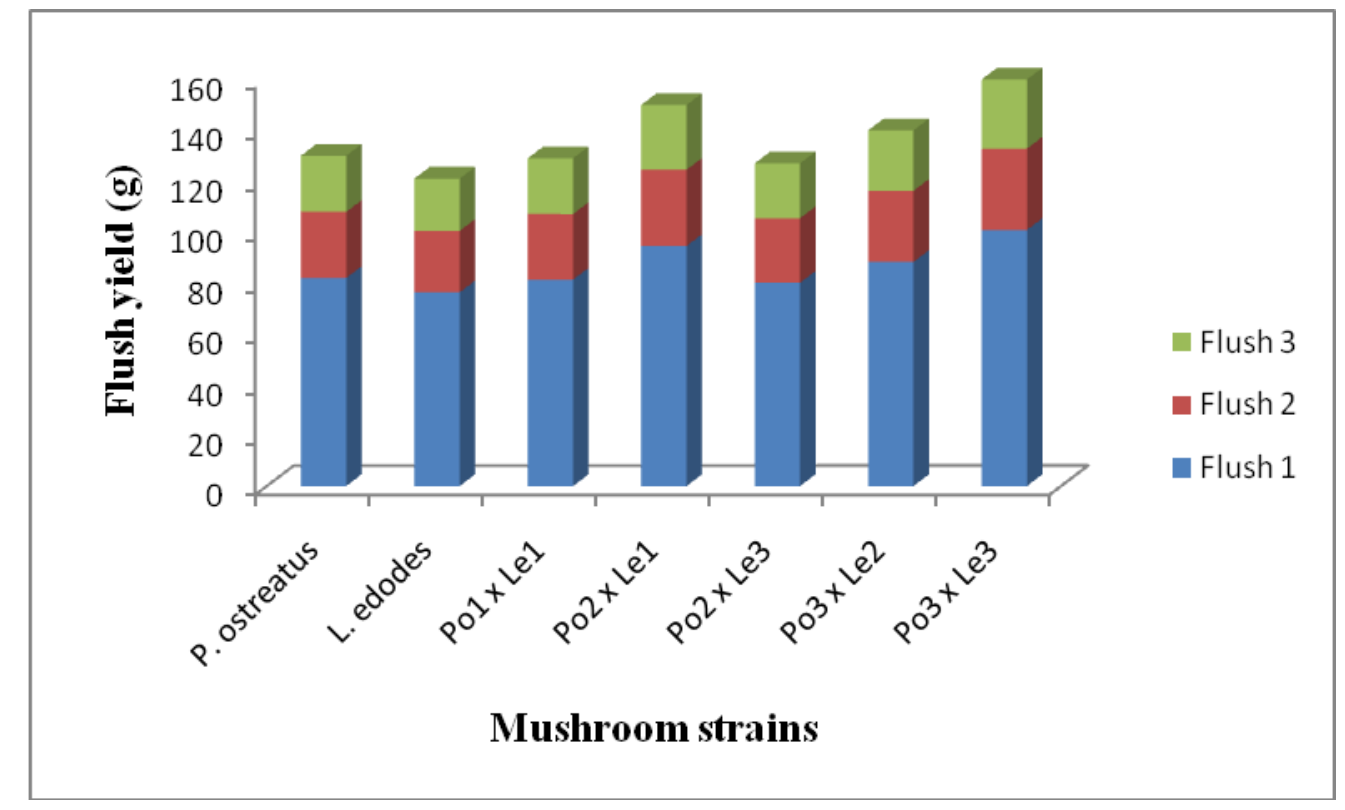

Figure 1: Flush yields at different periods of harvest in parents and new strains of mushroom derived from $P$. ostetreatus $x$ L. edodes cross.

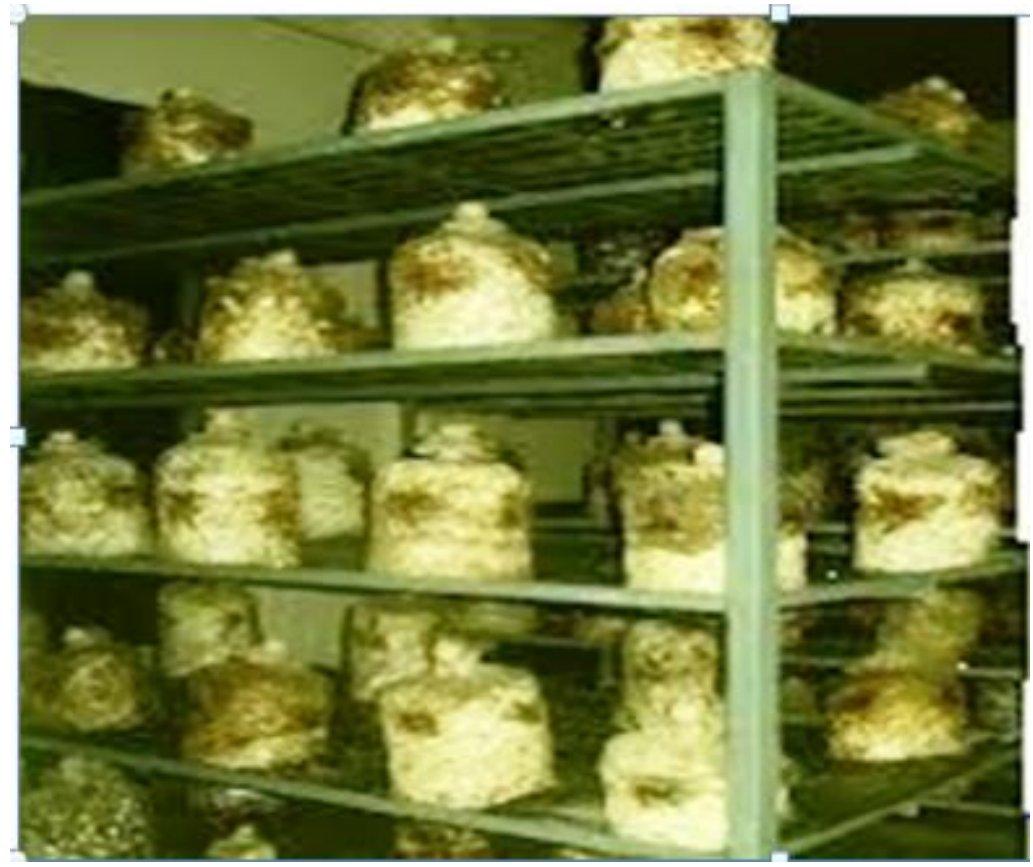

Plate 1: Development and fruiting of mushrooms in polyethylene bags inside growth room at room temperature. 

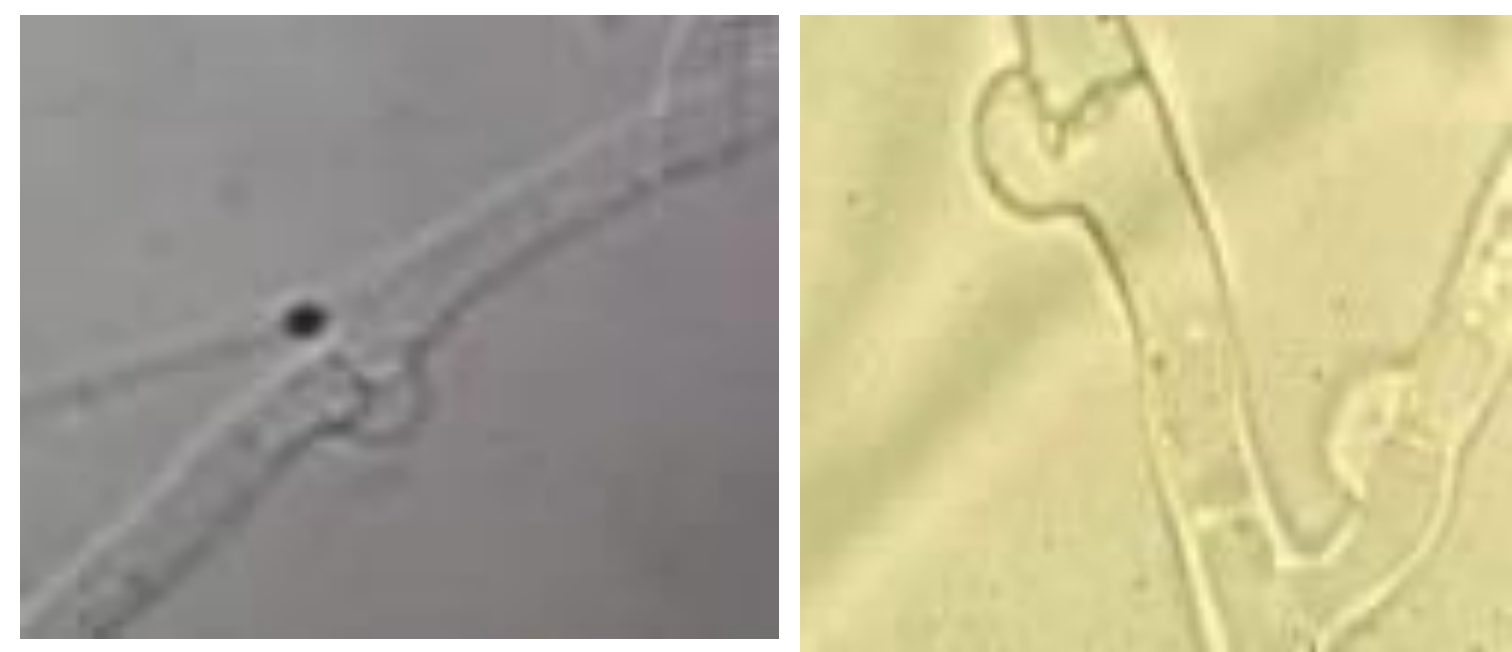

Plate 2: Clamp connection between P. osreatus and L. edodes at one point (left) and two points (right) under $100 \times$ magnifications.

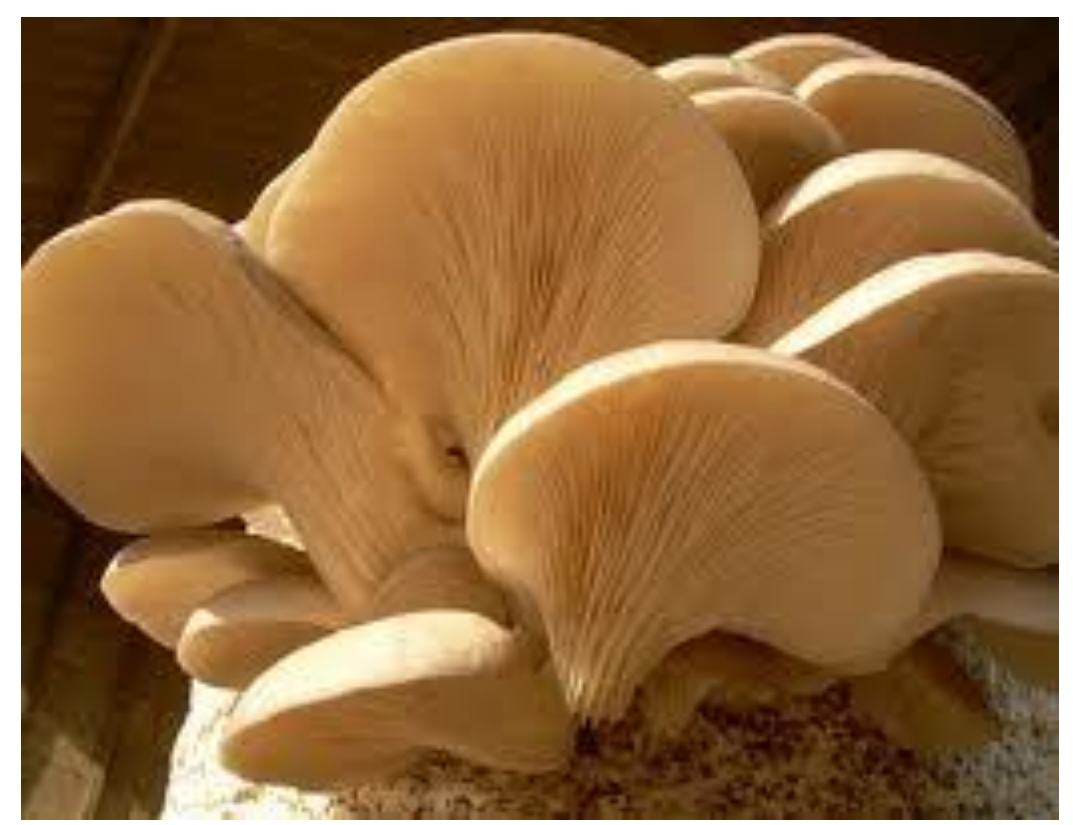

Plate 3: Basidiocarp developed from strain 5 of $P$. osreatus $x$ L. edodes cross. 


\section{REFERENCES}

Aswini, L., Arunagirinathan, N. and Kavitha, M. (2014). Strain improvement of Pleurotus species by protoplast fusion. International Journal of Advancements in Research and Technology, 3, 2278-7763.

Bak, W.C., Lee, T., Lee, W., Byon, B.H. and Kam, X.C. (1996). Selective breeding and hybridization of Letinus edodes strains for bed log cultivation. Journal of Korean Forestry Science, 85, 309-315.

Badalyan, S. M., Innocenti, G. and Garibyan, N.G. (2002). Antagonistic activity of xylotrophic mushrooms against pathogenic fungi of cereals in dual cultures. Phytopathologia Mediterranea, 41(3), 220-225.

Bllal, A.W., Bodha, R.H., and Wani, A.H. (2010). Nutritional and medicinal importance of mushrooms. Journal of Medicinal Plants Research, 4(24), 2598-2604.

Buah, J.N., Van der Puije, G.C., Bediako, E.A., Abole, E.A. and Showemimo, F. (2010). The growth and yield performance of oyster mushroom (Pleurotus osreatus) on different substrates. Biotechnology, 9(3), 338-342.

Chakraborty, U and Sikdar, S.R. (2010). Intergeneric protoplast fusion between Calocybe indica (milky mushroom) and Pleurotus florida aids in the qualitative and quantitative improvement of sporophore of the milky mushroom. World Journal of Microbiology and biotechnology, 26, 213-225.

Djajanegara, I. and Masduki, A. (2010). Protoplast fusion between white and brown oyster mushrooms. Indonesian Journal of Agricultural science, 11, 16-23.

Gaitán-Hernández, R. and Salmones, D. (2008). Obtaining and characterizing Pleurotus ostreatus strains for commercial cultivation under warm environmental conditions. Scientia Horticulturae, 118, 106-110.

Gregori, A., ŠVagelj, M. and Pohleven, J. (2007). Cultivation Techniques and Medicinal Properties of Pleurotus spp. Food Technology \& Biotechnology 45 (3), 238-249.

Jaradat, A.A. (2010). Genetic resources of energy crop: biological systems to combat climate change. Aust Journal of Crop Science, 4, 309323. 
Kumara, K.L.W. and Edrimanna, I.C.S. (2009). Improvement of strains of two oysher mushroom cultivars using duel culture technique. World Applied Sciences Journal, 7 (5), 654-660.

Larraya, L.M., Alfonso, M., Pisabarro, A.G. and Ramirez, L. (2003). Mapping of genomic regions (quantitative trait loci) controlling production and quality in industrial cultures of the edible basidiomycete Pleurotus ostreatus. Applied Environmental Microbiology, 69 (6), 3617-3625.

Luk, W.Y. and Chiu, S.W. (2005). Interspecific hybridization of Ganoderma lucidum and $G$. tsugae by protoplast fusion. Acta edulis fungi, (Supplement), 12, 528-534.

Masarirambi, M.T., Mamba, M. B. and Earnshaw, D.M. (2011). Effects of various substrates on growth and yield of oyster mushroom (Pleurotus ostreatus). Asian Journal of Agricultural Sciences, 3(4), 275-280.

Musakhail, S.W., Jiskani, M.M. and Bhatti, M.I. (2011). Growth and yield of oyster mushroom (Pleurotus ostreatus) as affected by gram powder amendment in substrate. Pakistani Journal of Phytopathology, 23(1), 35-41.

Okamura, T., Takeno, T., Dohi, M., Yasumasa, I., Hayashi, T., Toyoda, M., Noda, H., Fukuda, S., Horie, N. and Ohsugi, M. (2000). Development of mushrooms for thrombosis prevention by protoplast fusion. Journal of Bioscience and Bioengineering, 89, 474-478.

Okhoya, J.A., Akpaja, E.O., Osemwegie, O.O., Oghenekaro, A.O. and Ihayere, C.A. (2010). Nigerian mushrooms: Underutilized Non-wood forest resources. Journal of Applied Science Environmental Management, 4(1), 43-54.

Parani, K. and Eyini, M. (2010). Strain improvement through protoplast fusion for enhanced coffee pulp degradation. African Journal of Basic and Applied Sciences, 2(1-2), 37-41.

Patra, S., Maity, K. K., Bhunia, S. K., Dey, B., Mandal, S., Maiti, T. K., Sikdar, S. R. and Islam, S. S. (2011). Structural characterization and study of immunoenhancing properties of heteroglycan isolated from a somatic hybrid mushroom (PfloVv1aFB) of Pleurotus florida and Volvariella volvacea. Carbohydrate Research, 346, 1967-1972.

Ramirez-Carrillo, R., Marroquin-Corona, C. and Leal-Lara, H. (2011). Strain improvement of edible fungi with Pleurotus eryngii neohaplonts. Proceedings of the $7^{\text {th }}$ International Conference on Mushroom Biology 
and Mushroom Products (ICMBMP7), Beautiful Arcachon, France, $4^{\text {th }}$ $-7^{\text {th }}$ October, 2011, pp 62-70.

Roysne, D.J and Bahler, B.D. (1989). Yield and size of shiitake as influence by synthetic log diameter and genotype. Mushroom Journal for the Tropics, 9, 109-113.

Sánchez, C. (2010). Cultivation of Pleurotus ostreatus and other edible mushrooms. Applied Microbiology and Biotechnology, 85, 13211337

Sharma, R. and Sharma, B. M. (2014). Strain improvement in Pleurotus Ostreatus using UV light and ethyl methyl sulfonate as mutagens. African Journal of Microbiology Research, 8(5), 432-436.

Steel, R.G.D. and Torrie, J.H. (1980). Principle and procedures of statistics, New York: McGraw-Hill Books Co.

Vilgalys, R., Moncalvo, J.M., Liou, S.R. and Volovsek, M. (1996). Recent advances in molecular systematics of the genus Pleurotus. InMushroom Biology and Mushroom Products. (ed.) Royse. Penn State University Press, University Park, pp. 91-101.

Wang, D., Sakoda, A. and Suzuki, M. (2001). Biological efficiency and nutritional value of Pleurotus ostreatus cultivated on spent beer grain. Bioresource technology Oxford, U.K. Elsevier ci. Ltd. 78(3):293-300.

Yang, X.M. (1986). Cultivation of edible mushroom in China. Agricultural Printing House, Beijing, China. 